\title{
(-)-Epigallocatechin-3-gallate modulates peripheral immunity in the MPTP-induced mouse model of Parkinson's disease
}

\author{
TINGTING ZHOU ${ }^{1}$, MENGRU ZHU ${ }^{2}$ and ZHANHUA LIANG ${ }^{1}$ \\ ${ }^{1}$ Department of Neurology, The First Affiliated Hospital of Dalian Medical University, Dalian, Liaoning 116011; \\ ${ }^{2}$ Department of Plastic Surgery, China Medical University, Shenyang, Liaoning 110001, P.R. China
}

Received April 15, 2016; Accepted March 16, 2017

DOI: $10.3892 / \mathrm{mmr} .2018 .8470$

\begin{abstract}
Epigallocatechin-3-gallate (EGCG) is the most widely studied catechin in green tea and has been identified to regulate immune function. The objective of the present study was to explore the possible application of EGCG in the treatment of Parkinson's disease (PD) by examining its effects on the peripheral immune system in the 1-methyl-4-phenyl-1,2,3,6-tetrahydropyridine (MPTP)-induced PD mouse model. The results demonstrated that EGCG treatment restored the movement behavior of the mice impaired by MPTP, and protected tyrosine hydroxylase-positive cells in the substantia nigra pars compacta region from MPTP toxicity. Flow cytometric analysis indicated that the ratio of $\mathrm{CD}^{+} \mathrm{CD}^{+}$to $\mathrm{CD}^{+}{ }^{+} \mathrm{CD} 8^{+} \mathrm{T}$ lymphocytes in the peripheral blood increased in MPTP-treated mice following treatment with EGCG, and EGCG reduced expression of inflammatory factors tumor necrosis factor- $\alpha$ and interleukin- 6 in serum. The present findings indicated that EGCG serves neuroprotective effects in an MPTP-induced PD mice model and may exert this through modulating peripheral immune response.
\end{abstract}

\section{Introduction}

Parkinson's disease (PD) is the second most prevalent neurodegenerative disease worldwide after Alzheimer's disease (1). PD is characterized by the loss of dopaminergic neurons in the substantia nigra pars compacta (SNpc) and decreased dopamine levels in the striatum of the basal ganglia (2). Although decades of research have seen advancements in the field, the precise mechanisms underlying the pathogenesis of PD remains to be fully elucidated (3). However, studies conducted

Correspondence to: Professor Zhanhua Liang, Department of Neurology, The First Affiliated Hospital of Dalian Medical University, 222 Zhongshan Road, Dalian, Liaoning 116011, P.R. China

E-mail: zhanhualiangdl@163.com

Key words: Parkinson's disease, (-)-Epigallocatechin-3-gallate, peripheral immunity, neuroprotection, immunomodulatory over the last decades, including age, epidemiological, environmental toxins, genetic, immune dysfunction and postmortem studies, have contributed significantly to the understanding of the PD pathogenesis (4-6). Understanding these mechanisms may provide us the future disease-modifying strategies.

In recent decades, peripheral inflammation has been considered to increases the deleterious effect of CNS inflammation on the nigrostriatal dopaminergic cells $(7,8)$, and the peripheral immunity has been recognized to increase the central inflammation in neurodegenerative processes (9). Considering the deleterious role of peripheral inflammation in PD development, immunomodulation as a neuroprotective and therapeutic strategy is thought to be a novel method for Parkinson's disease (10). Thus, it is may be a new therapeutic approach to investigate PD from an immunological perspective to alleviate the disease.

Treatment of PD has attracted big interest because the prevention of PD is still a challenge for physicians. Previous studies have reported that greentea polyphenol,(-)-epigallocatechin-3-gallate (EGCG), prevented 1-methyl-4-phenyl-1,2,3,6-tetrahydropyridine (MPTP)-induced loss of dopaminergic neurons in the substantia nigra, which was concomitant with a depletion in striatal dopamine and tyrosine hydroxylase $(\mathrm{TH})$ protein levels (11). Another study demonstrated that the protective effects of EGCG in the MPTP mouse model of PD was via inhibiting neuronal nitric oxide synthase in the substantia nigra (12). Moreover, EGCG has immunomodulatory effects in many disease models, including nerve system disease (13-15). Therefore, the present study investigated the neuroprotective effect of EGCG and the peripheral immune response changes in the MPTP-induced PD mouse model, which will hopefully identify the possible targets of EGCG in PD.

\section{Materials and methods}

Ethics statement. All animal experiments were performed in strict accordance with the recommendations in the Guide for the Care and Use of Laboratory Animals of the National Institutes of Health (Bethesda, MD, USA). The animal protocols were approved by the Committee on the Ethics of Animal Experiments of the Dalian Medical University (Dalian, China).

Animals and treatment. C57BL/6J mice (6-8 weeks old, male, weighing 16-25 g) purchased from the Experimental 
Animal Center of Dalian Medical University (Dalian, China; SPF level) were used for the present study. Mice were maintained at a constant temperature of $20-22^{\circ} \mathrm{C}$ under a $12 \mathrm{~h} \mathrm{light/dark} \mathrm{cycle} \mathrm{of} \mathrm{artificial} \mathrm{light} \mathrm{and} \mathrm{had} \mathrm{free} \mathrm{access}$ to food and water. The 20 mice were randomly divided into four groups with five per group: i) The control group, ii) the MPTP (30 mg/kg/day) group, iii) the MPTP+EGCG (MTPT dose of $30 \mathrm{mg} / \mathrm{kg} /$ day; EGCG dose of $25 \mathrm{mg} / \mathrm{kg} /$ day) group; and iv) the MPTP+EGCG (MTPT dose of $30 \mathrm{mg} / \mathrm{kg} / \mathrm{day}$; EGCG dose of $50 \mathrm{mg} / \mathrm{kg} / \mathrm{day}$ ) group. The subchronic method was used to establish the MPTP-induced PD mouse model (16). MPTP groups were administered intraperitoneal injections of MPTP-HCl (Sigma-Aldrich; Merck KGaA, Darmstadt, Germany) in saline once daily at a dosage of $30 \mathrm{mg} / \mathrm{kg} /$ day for 5 consecutive days. The remaining groups were administered intraperitoneal injections of saline. EGCG $(\geq 97 \%$ ) was purchased from Sigma-Aldrich; Merck KGaA, the chemical structure of EGCG is presented in Fig. 1. The doses of EGCG ( 25 and $50 \mathrm{mg} / \mathrm{kg}$ ) was chosen according to the previous article (17). EGCG in water was administered from 1 day prior to MPTP treatment to the day 20 after MPTP injection with gavage.

Behavior test. The mice in the PD groups performed the 'pole test' to assess motor coordination 1 day prior to MPTP injection and on the 5,10,15 and 20th day following the last MPTP injection. Mice were trained 3 days before MPTP injection (18). The 'pole test' consisted of a gauze-taped pole (50 cm high, $1 \mathrm{~cm}$ in diameter) with a small cork ball at the top. Mice were placed with their head facing upwards immediately below the ball. Two times were recorded: The time it took for the mouse to turn completely downward (T-turn) and the time it took to descend to the floor (T-total), with a cut-off limit of $60 \mathrm{sec}$. The test was performed 3 times at $10 \mathrm{~min}$ intervals, and the average time was recorded.

Blood sample preparation. Peripheral blood was drawn following the last day treatment of each group. All of the mice were anesthetized and $0.5-0.6 \mathrm{ml}$ peripheral blood was drawn through the angular vein. Serum was separated from the whole blood at $4^{\circ} \mathrm{C}$ by centrifugation at $400 \mathrm{x} \mathrm{g}$ for $10 \mathrm{~min}$, subpackaged in an EP tube and stored at $-80^{\circ} \mathrm{C}$ until processed for ELISA analysis. Peripheral blood mononuclear cells (PBMCs) were isolated with deionized water as a lysate, incubated with fluorescently labeled antibodies against $\mathrm{CD}^{+}, \mathrm{CD}^{+}$and/or $\mathrm{CD}^{+} \mathrm{T}$ cells (cat. nos. 100309 , 100405, and 100707; BioLegend, Inc., San Diego, CA, USA) according to the manufacturer's instructions, washed twice with $0.01 \mathrm{M}$ PBS ( $\mathrm{pH}=7.4)$ and prepared for flow cytometric analysis.

Brain tissue preparation. Brain tissue was dissected from mice from each group following treatment. All of the mice were anesthetized and rapidly perfused through the aorta with saline for $10 \mathrm{~min}$, followed by $4^{\circ} \mathrm{C}$ precooled $4 \%$ paraformaldehyde for $10 \mathrm{~min}$. The mice were then decapitated, and their brains were rapidly removed and post-fixed by immersion in $4 \%$ paraformaldehye at $4^{\circ} \mathrm{C}$ for $12 \mathrm{~h}$. Finally, the brain was sequentially dehydrated with 20 and $30 \%$ sucrose in $0.1 \mathrm{M}$ PBS for immunofluorescence.
Table I. Concentrations of TNF- $\alpha$ and IL-6 in blood serum (pg/ml).

\begin{tabular}{lccc}
\hline Group & $\mathrm{n}$ & TNF- $\alpha$ & IL-6 \\
\hline Control & 8 & $445.35 \pm 17.13$ & $96.50 \pm 7.89$ \\
MPTP & 8 & $670.34 \pm 33.06^{\mathrm{a}}$ & $126.55 \pm 8.74^{\mathrm{a}}$ \\
MPTP+EGCG & & & \\
$(25 \mathrm{mg} / \mathrm{kg})$ & 8 & $456.83 \pm 31.81^{\mathrm{b}}$ & $108.12 \pm 7.18^{\mathrm{b}}$ \\
$\begin{array}{l}\text { MPTP+EGCG } \\
(50 \mathrm{mg} / \mathrm{kg})\end{array}$ & 8 & $447.57 \pm 14.30^{\mathrm{b}}$ & $102.83 \pm 6.69^{\mathrm{b}}$ \\
\hline
\end{tabular}

${ }^{a} \mathrm{P}<0.05$ vs. control group and ${ }^{\mathrm{b}} \mathrm{P}<0.05$ vs. MPTP group $(\mathrm{n}=8)$. TNF- $\alpha$, tumor necrosis factor- $\alpha$; IL, interleukin; MPTP, 1-methyl-4-pheny 1-1,2,3,6-tetrahydropyridine; EGCG, (-)-Epigallocatechin-3-gallate.<smiles>O=C(O[C@H]1Cc2c(O)cc(O)cc2O[C@@H]1c1cc(O)c(O)c(O)c1)c1cc(O)c(O)c(O)c1</smiles>

Figure 1. Chemical structure of (-)-Epigallocatechin-3-gallate.

Immunofluorescence. Brain sections (20 $\mu \mathrm{m}$ thick) were cut at $-20^{\circ} \mathrm{C}$ following dehydration with 20 and $30 \%$ sucrose in $0.1 \mathrm{M}$ PBS, and were then mounted on glass slides. The sections were microwaved twice and then cooled at room temperature for $30 \mathrm{~min}$. The sections were then rinsed 3 times and incubated in $0.3 \%$ Triton X-100 for $30 \mathrm{~min}$. After washing in PBS, the sections were blocked for $30 \mathrm{~min}$ at $37^{\circ} \mathrm{C}$ with $10 \%$ normal goat serum (cat. no. SL039; 1:10; Beijing Solarbio Science \& Technology, Co., Ltd., Beijing, China). The sections were then incubated with mouse anti-tyrosine hydroxylase (cat. no. 22941; 1:4,000; ImmunoStar, Inc., Hudson, WI, USA) at $4^{\circ} \mathrm{C}$ for $16-24 \mathrm{~h}$. With overnight incubation, the sections were rinsed and incubated in the dark for $2 \mathrm{~h}$ with tetramethylrhodamine-conjugated goat anti-mouse (cat. no. 115-025-003; 1:500; Jackson ImmunoResearch Laboratories, Inc., West Grove, PA, USA). After washing, the slides were coverslipped. Images were taken using a fluorescence microscope (Leica DM4000B, Leica, Wetzlar, Germany). Positive cells were measured using image analysis software (ImageJ, version, 1.46; National Institutes of Health, Bethesda, MD, USA).

Flow cytometric analysis. Following centrifugation at $4^{\circ} \mathrm{C}$ and $400 \mathrm{x} \mathrm{g}$ for $10 \mathrm{~min}$, each sample was resuspended in $500 \mu \mathrm{l}$ of $0.01 \mathrm{M}$ PBS ( $\mathrm{pH}=7.4$ at a density of $1 \times 10^{6}$ cells/100 $\mu \mathrm{l}$ ) and analyzed using a FAC Scan flow cytometer (BD Biosciences, 
A

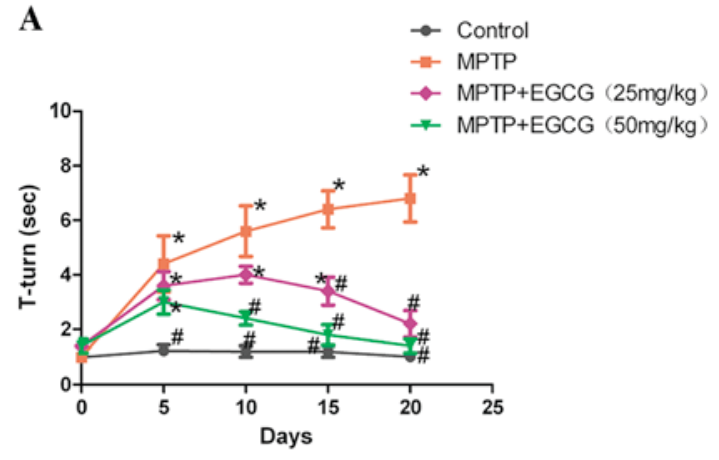

B

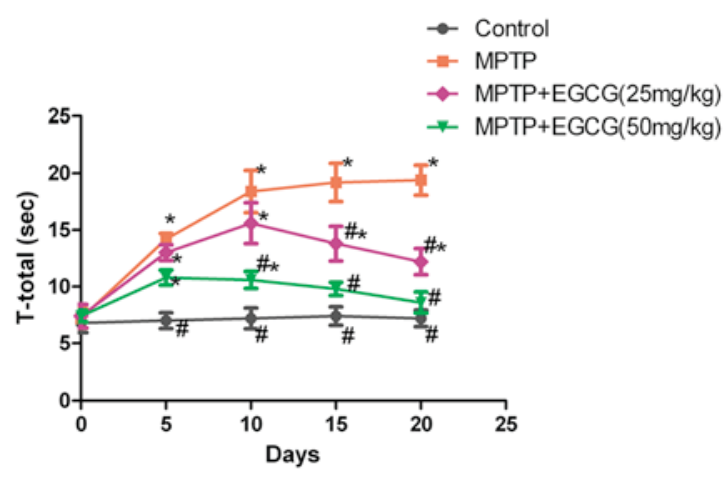

Figure 2. Effect of EGCG on the T-turn and T-total times. (A) T-turn. (B) T-total. Data are presented as the mean \pm standard error of the mean (n=5). $\mathrm{P}<0.05$ vs. control group; ${ }^{\mathrm{P}}<0.05$ vs. MPTP group. EGCG, (-)-Epigallocatechin-3-gallate; MPTP, 1-methyl-4-phenyl-1,2,3,6-tetrahydropyridine.

Franklin Lakes, NJ, USA). PBMCs were stained at room temperature for 30 min with PE-Cy5-conjugated anti-CD3 ${ }^{+}$ (cat. no. 100309; BioLegend, Inc.), fluorescein isothiocyanate-conjugated anti-CD4+ (cat. no. 100405; BioLegend, Inc.), and phycoerythrin-conjugated anti-CD8 ${ }^{+}$(cat. no. 100707; BioLegend, Inc.) antibodies. The data analysis was performed using CellQuest software (version 5.1; BD Biosciences), and the results are expressed as the percentage of cells in a gated $\mathrm{T}$ cell region. $\mathrm{CD}^{+}$and $\mathrm{CD}^{+} \mathrm{T}$ cells were gated on $\mathrm{CD}^{+} \mathrm{T}$ cells.

ELISA analysis. Concentrations of tumor necrosis factor (TNF)- $\alpha$ and interleukin (IL)- 6 in the blood serum were determined by ELISA using commercially available kits (cat. nos. 410-TRNC-050/CF and 406-ML-005/CF; R\&D Systems, Inc., Minneapolis, MN, USA). Standard, control and test samples were added to each well and incubated for the appropriate times with associated primary antibodies and conjugates, in accordance with the manufacturer's protocol (R\&D Systems, Inc.). After washing four times, the substrate solution was added to each well, and the reactions were incubated for $30 \mathrm{~min}$ at room temperature in the dark. Finally, the reactions were terminated by the addition of stop solution, and the optical density of each well was determined at a wavelength of $450 \mathrm{~nm}$ using a microplate reader (AD340; BioTek Instruments, Inc., Winooski, VT, USA).

Statistical analysis. All quantitative data were analyzed using SPSS software (version, 17.0; SPSS, Inc., Chicago, IL, USA). The results are expressed as the means \pm standard error of the mean. The data were analyzed using a one-way analysis of variance, followed by Tukey's multiple comparison test. $\mathrm{P}<0.05$ was considered to indicate a statistically significant difference. All statistical analyses in this study were performed using Prism 5 for Windows, version 5.01 (GraphPad Software, Inc., La Jolla, CA, USA).

\section{Results}

Effects of EGCG on behavior in the 'pole test'. The motor dysfunction in the MPTP-induced PD model was used to study the dopaminergic neuron degeneration and the motor activity. The authors used the 'pole test' to assess whether the MPTP-induced PD model was successful for bradykinesia. As presented in Fig. 2, the effect of EGCG on the behavior of mice was compared to the non-treated groups. Time of 'T-turn' and 'T-total' significantly increased following given MPTP $(\mathrm{P}<0.05)$ and were reduced with administration of EGCG $(\mathrm{P}<0.05)$.

Effects of EGCG on tyrosine hydroxylase (TH)-positive cells. The TH-positive neurons in the SNpc region, which are the phenotypic marker for dopaminergic neurons, were used to estimate the neuronal protection of EGCG in the MPTP-induced mouse model. The number of $\mathrm{TH}$-positive neurons in the SNpc region was determined by counting the number of TH-positive cells. As demonstrated in Fig. 3, MPTP-treated mice exhibited a significant reduction in the number of TH-positive neurons compared with the control group $(\mathrm{P}<0.05)$. However, when MPTP was combined with EGCG treatment, the number of TH-positive neurons significantly increased compared with that in the MPTP-treated group $(\mathrm{P}<0.05)$.

Effects of EGCG on $\mathrm{CD}^{+} C D 4^{+}$and $C D 3^{+} C D 8^{+}$T cells in the peripheral blood. To evaluate the adaptive immunity changes in MPTP-treated mice and the therapeutic effect of EGCG, the authors analyzed $\mathrm{CD} 3^{+} \mathrm{T}$ cells, $\mathrm{CD} 3^{+} \mathrm{CD} 4^{+} \mathrm{T}$ cells, and $\mathrm{CD}^{+}{ }^{+} \mathrm{CD} 8^{+} \mathrm{T}$ cells to represent the level of adaptive immunity. The results are presented in Fig. 4. The percentage of $\mathrm{CD}^{+} \mathrm{CD}^{+} \mathrm{T}$ cells was lower $(\mathrm{P}<0.05$; Fig. 4B) and the percentage of $\mathrm{CD}^{+} \mathrm{CD}^{+} \mathrm{T}$ cells was higher $(\mathrm{P}<0.05$; Fig. $4 \mathrm{C})$ in MPTP mice than in controls. The ratio of $\mathrm{CD}^{+} \mathrm{CD} 4^{+}$to $\mathrm{CD}^{+} \mathrm{CD}^{+} \mathrm{T}$ cells was lower $(\mathrm{P}<0.05)$ in MPTP mice than in controls (Fig. 4D). Whereas, with the EGCG treatment, the results were reversed.

Effects of EGCG on TNF- $\alpha$ and IL-6 in the serum. To further assess the effects of EGCG combined with MPTP on the secretion of proinflammatory cytokines in PD mice, the serum levels of TNF- $\alpha$ and IL- 6 were tested. As presented in (Table I) and (Fig. 5), the levels of TNF- $\alpha$ and IL-6 significantly increased in the MPTP mice compared with the control mice $(\mathrm{P}<0.05)$. With EGCG treatment, the levels of TNF- $\alpha$ and IL- 6 significantly decreased compared with the MPTP mice $(\mathrm{P}<0.05)$.

\section{Discussion}

Previous studies have indicated that peripheral inflammation occurs in PD and accelerates disease progression $(19,20)$. 
A

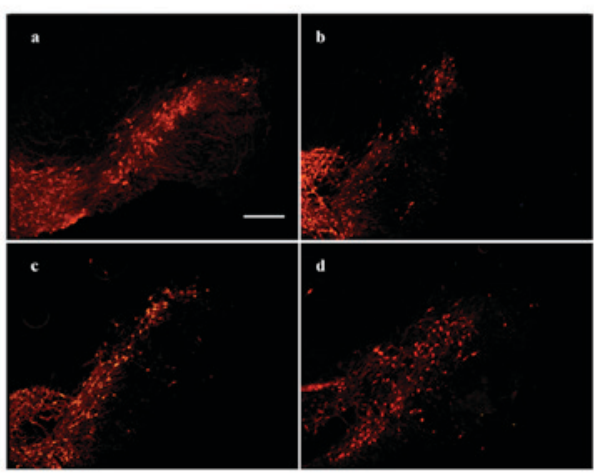

B

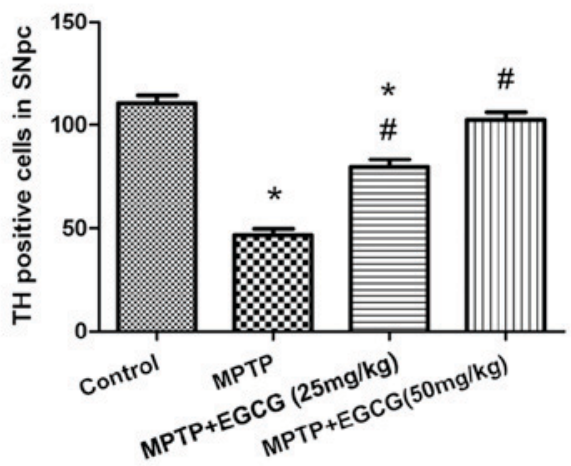

Figure 3. Effect of EGCG on SNpc dopaminergic neurons following MPTP treatment. (A) Immunofluorescence of TH. (a) control group; (b) MPTP group; (c) MPTP+EGCG (25 mg/kg) group; (d) MPTP+EGCG (50 mg/kg) group. Magnification, x100. (B) The number of TH-positive cells in the SNpc. "P<0.05 vs. control group and ${ }^{\#} \mathrm{P}<0.05$ vs. MPTP group. Data are presented as the mean \pm standard error of the mean (n=5). EGCG, (-)-Epigallocatechin-3-gallate; MPTP, 1-methyl-4- phenyl-1,2,3,6-tetrahydropyridine; SNpc, substantia nigra pars compacta.

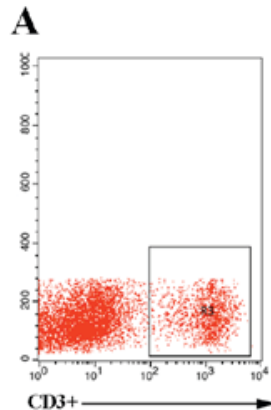

B

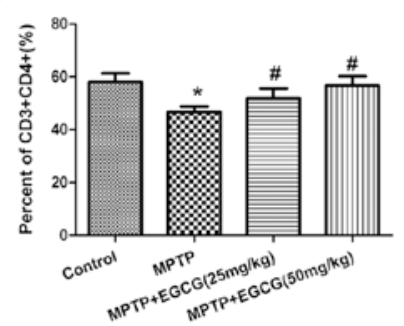

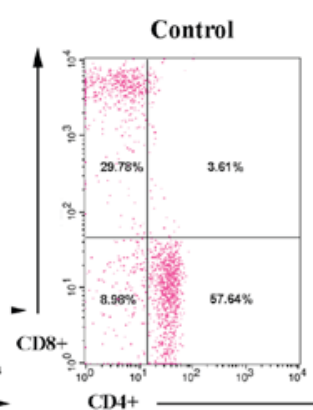
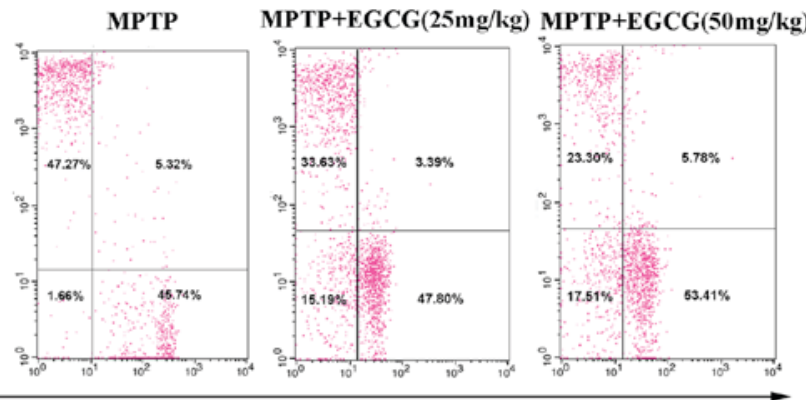

$\mathrm{C}$

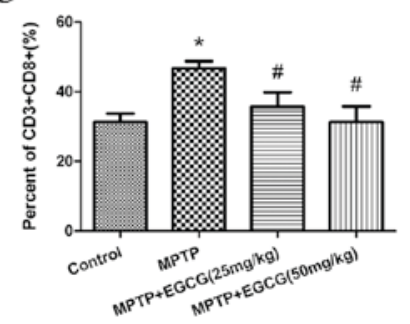

D

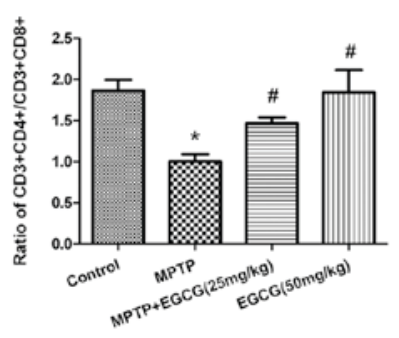

Figure 4. Effects of EGCG on the level of $\mathrm{CD}^{+} \mathrm{CD} 4^{+} \mathrm{T}$ cells and $\mathrm{CD} 3^{+} \mathrm{CD} 8^{+} \mathrm{T}$ cells. The red and pink dots represent $\mathrm{T}$ cells. (A) The $\mathrm{CD} 4^{+} \mathrm{T}$ cells and $\mathrm{CD} 8^{+}$ $\mathrm{T}$ cells are gated in $\mathrm{CD}^{+} \mathrm{T}$ cell region. (B) $\mathrm{CD}^{+} \mathrm{CD}^{+} \mathrm{T}$ cells. (C) $\mathrm{CD} 3^{+} \mathrm{CD} 8^{+} \mathrm{T}$ cells. (D) The ratio of $\mathrm{CD}^{+} \mathrm{CD}^{+} / \mathrm{CD} 3^{+} \mathrm{CD} 8^{+} \mathrm{T}$ cells. ${ }^{*} \mathrm{P}<0.05$ vs. control group and " $\mathrm{P}<0.05$ vs. MPTP group. Data are presented as the mean \pm standard error of the mean ( $\mathrm{n}=5)$. EGCG, (-)-Epigallocatechin-3-gallate; MPTP, 1-methyl-4-phenyl-1,2,3,6-tetrahydropyridine.

A

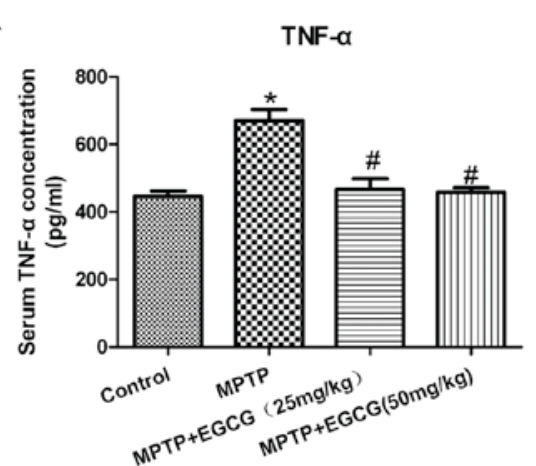

B

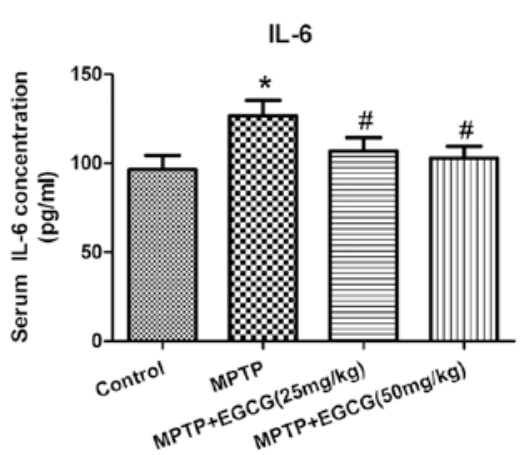

Figure 5. Effect of EGCG on (A) TNF- $\alpha$ and (B) IL-6 concentrations in blood serum. ${ }^{*} \mathrm{P}<0.05$ vs. control group and ${ }^{*} \mathrm{P}<0.05$ vs. MPTP group. Data are presented as the mean \pm standard error of the mean ( $\mathrm{n}=5$ ). EGCG, (-)-Epigallocatechin-3-gallate; MPTP, 1-methyl-4-phenyl-1,2,3,6-tetrahydropyridine; TNF- $\alpha$, tumor necrosis factor- $\alpha$; IL, interleukin. 
Some nonsteroidal anti-inflammatory drugs have been suggested to protect against PD progression and have been associated with a lower PD risk (21). In the last decade, some of these herbal medicines have been considered to be therapeutic agents in PD models via their modulation of certain factors implicated in PD pathogenesis (22-24). EGCG is the most widely studied catechin in green tea and has been indicated to regulate immune function (13). Although EGCG has long been used to improve immune system function (25), the peripheral immunomodulatory effect of EGCG has not been studied in an MPTP-induced PD mouse model.

In the present study, the authors established the PD mouse model induced by MPTP, which could cause dopaminergic neuronal loss in the SNpc and lead to motor deficits in mice (26). Consistent with reports before, the 'pole test' indicated that the motor function of the PD mice was impaired and EGCG restored the motor dysfunction. The authors further examined the number of TH-positive dopaminergic neurons to assess the neuroprotective role of EGCG, and the results indicated that the dopaminergic neurons of the PD mice reduced and EGCG prevented the loss of the neurons. These results indicated that EGCG exerted behavior restoration and protected dopaminergic neurons from MPTP-induced degeneration.

Previous research has implicated peripheral inflammation in neurodegenerative diseases. Increasing studies have demonstrated that peripheral immune system activation exacerbates the CNS inflammatory response and accelerates neurodegeneration in PD (26). It has been reported that, in peripheral blood, $\mathrm{CD}^{+} \mathrm{T}$ cells decreased and $\mathrm{CD} 8^{+} \mathrm{T}$ cells increased were observed in mouse model $(27,28)$. In the current study, the ratio of $\mathrm{CD}^{+} \mathrm{CD}^{+}$to $\mathrm{CD}^{+} \mathrm{CD}^{+} \mathrm{T}$ cells decreased, which indicated altered $\mathrm{T}$ cell function in MPTP mice, whereas with EGCG treatment, the results were reversed. These results suggested that $\mathrm{CD}^{+} \mathrm{CD}^{+}{ }^{+}$to $\mathrm{CD}^{+} \mathrm{CD}^{+} \mathrm{T}$ cells altered in the MPTP-induced PD mice, and EGCG successfully reversed this dysfunction.

Cytokines are small proteins that function in inflammatory processes and in the regulation of the immune system (29). In addition, the role of proinflammatory cytokines in the serum of MPTP-treated mice was investigated. Studies reported that elevated serum concentrations of TNF- $\alpha$ and IL- 6 correlated with an increased risk of PD (7,30), which is consistent with a previous study (31). In the present study, the serum concentrations of TNF- $\alpha$ and IL- 6 were elevated in PD mice and decreased in EGCG mice. These results suggested that EGCG could reduce proinflammatory cytokines in the PD mouse model and may be helpful in reducing the dopaminergic neurons death, and its modulation may represent a new therapeutic approach for PD.

In conclusion, the authors demonstrated that the neuroprotective and immunoprotective effects of EGCG in MPTP-treated mice. These results indicated that EGCG could modulate the peripheral inflammation and protect dopaminergic neurons loss in MPTP PD model. However, the underlying molecular mechanism of the immunological effects of EGCG remain unclear, future studies will include the mechanisms responsible for immunomodulation of EGCG.

\section{References}

1. Dauer W and Przedborski S: Parkinson's disease: Mechanisms and models. Neuron 39: 889-909, 2003.

2. Jenner $\mathrm{P}$ and Olanow $\mathrm{CW}$ : The pathogenesis of cell death in Parkinson's disease. Neurology 66 (10 Suppl 4): S24-S36, 2006.

3. Chau KY, Ching HL, Schapira AH and Cooper JM: Relationship between alpha synuclein phosphorylation, proteasomal inhibition and cell death: Relevance to Parkinson's disease pathogenesis. J Neurochem 110: 1005-1013, 2009.

4. Lees AJ, Hardy J and Revesz T: Parkinson's disease. Lancet 373: 2055-2066, 2009.

5. Badger JL, Cordero-Llana O, Hartfield EM and Wade-Martins R: Parkinson's disease in a dish-Using stem cells as a molecular tool. Neuropharmacology 76: 88-96, 2014.

6. Dexter DT and Jenner P: Parkinson disease: From pathology to molecular disease mechanisms. Free Radic Biol Med 62: 132-144, 2013.

7. Hernández-Romero MC, Delgado-Cortés MJ, Sarmiento M, de Pablos RM, Espinosa-Oliva AM, Argüelles S, Bández MJ, Villarán RF, Mauriño R, Santiago M, et al: Peripheral inflammation increases the deleterious effect of CNS inflammation on the nigrostriatal dopaminergic system. Neurotoxicology 33: 347-360, 2012.

8. Chen H, O'Reilly EJ, Schwarzschild MA and Ascherio A: Peripheral inflammatory biomarkers and risk of Parkinson's disease. Am J Epidemiol 167: 90-95, 2008.

9. Amor S and Woodroofe MN: Innate and adaptive immune responses in neurodegeneration and repair. Immunology 141: 287-291, 2014.

10. Olson KE and Gendelman HE: Immunomodulation as a neuroprotective and therapeutic strategy for Parkinson's disease. Curr Opin Pharmacol 26: 87-95, 2016.

11. Levites Y, Weinreb O, Maor G, Youdim MB and Mandel S: Green tea polyphenol (-)-epigallocatechin-3-gallate prevents $\mathrm{N}$-methyl-4-phenyl-1,2,3,6-tetrahydropyridine-induced dopaminergic neurodegeneration. J Neurochem 78: 1073-1082, 2001

12. Choi JY, Park CS, Kim DJ, Cho MH, Jin BK, Pie JE and Chung WG: Prevention of nitric oxide-mediated 1-methyl-4-phenyl-1,2,3,6-tetrahydropyridine-induced Parkinson's disease in mice by tea phenolic epigallocatechin 3-gallate. Neurotoxicology 23: 367-374, 2002.

13. Kuo CL, Chen TS, Liou SY and Hsieh CC: Immunomodulatory effects of EGCG fraction of green tea extract in innate and adaptive immunity via $\mathrm{T}$ regulatory cells in murine model. Immunopharmacol Immunotoxicol 36: 364-370, 2014.

14. Yoneyama S, Kawai K, Tsuno NH, Okaji Y, Asakage M, Tsuchiya T, Yamada J, Sunami E, Osada T, Kitayama J, et al: Epigallocatechin gallate affects human dendritic cell differentiation and maturation. J Allergy Clin Immunol 121: 209-214, 2008.

15. Kuang X, Huang Y, Gu HF, Zu XY, Zou WY, Song ZB and Guo QL: Effects of intrathecal epigallocatechin gallate, an inhibitor of Toll-like receptor 4, on chronic neuropathic pain in rats. Eur J Pharmacol 676: 51-56, 2012.

16. Jackson-Lewis V and Przedborski S: Protocol for the MPTP mouse model of Parkinson's disease. Nat Protoc 2: 141-151, 2007.

17. Wei IH, Wu YC, Wen CY and Shieh JY: Green tea polyphenol (-)-epigallocatechin gallate attenuates the neuronal NADPH-d/nNOS expression in the nodose ganglion of acute hypoxic rats. Brain Res 999: 73-80, 2004.

18. Sedelis M, Schwarting RK and Huston JP: Behavioral phenotyping of the MPTP mouse model of Parkinson's disease. Behav Brain Res 125: 109-125, 2001.

19. Stone DK, Reynolds AD, Mosley RL and Gendelman HE: Innate and adaptive immunity for the pathobiology of Parkinson's disease. Antioxid Redox Signal 11: 2151-2166, 2009.

20. McGeer PL and McGeer EG: Inflammation and the degenerative diseases of aging. Ann N Y Acad Sci 1035: 104-116, 2004.

21. Wahner AD, Bronstein JM, Bordelon YM and Ritz B: Nonsteroidal anti-inflammatory drugs may protect against Parkinson disease. Neurology 69: 1836-1842, 2007.

22. Choi JG, Kim HG, Kim MC, Yang WM, Huh Y, Kim SY and Oh MS: Polygalae radix inhibits toxin-induced neuronal death in the Parkinson's disease models. J Ethnopharmacol 134: 414-421, 2011.

23. Hwang DS, Kim HG, Kwon HJ, Cho JH, Lee CH, Lee JM, Jang JB, Kim YS, Lee KS and Oh MS: Dangguijakyak-san, a medicinal herbal formula, protects dopaminergic neurons from 6-hydroxydopamine-induced neurotoxicity. J Ethnopharmacol 133: 934-939, 2011. 
24. Lu C, Zhang J, Shi X, Miao S, Bi L, Zhang S, Yang Q, Zhou X, Zhang M, Xie Y, et al: Neuroprotective effects of tetramethylpyrazine against dopaminergic neuron injury in a rat model of Parkinson's disease induced by MPTP. Int J Biol Sci 10: 350-357, 2014.

25. Katiyar SK, Challa A, McCormick TS, Cooper KD and Mukhtar H: Prevention of UVB-induced immunosuppression in mice by the green tea polyphenol (-)-epigallocatechin-3-gallate may be associated with alterations in IL-10 and IL-12 production. Carcinogenesis 20: 2117-2124, 1999.

26. Goldberg NR, Haack AK, Lim NS, Janson OK and Meshul CK: Dopaminergic and behavioral correlates of progressive lesioning of the nigrostriatal pathway with 1-methyl-4-phenyl-1,2,3,6-tetrahydropyridine. Neuroscience 180: 256-271, 2011.

27. Amor S, Peferoen LA, Vogel DY, Breur M, van der Valk P, Baker D and van Noort JM: Inflammation in neurodegenerative diseases-an update. Immunology 142: 151-166, 2014.
28. Bas J, Calopa M, Mestre M, Molleví DG, Cutillas B, Ambrosio S and Buendia E: Lymphocyte populations in Parkinson's disease and in rat models of parkinsonism. J Neuroimmunol 113: 146-152, 2001.

29. Dinarello CA: Historical insights into cytokines. Eur J Immunol 37 (Suppl 1): S34-S45, 2007.

30. Koziorowski D, Tomasiuk R, Szlufik S and Friedman A: Inflammatory cytokines and NT-proCNP in Parkinson's disease patients. Cytokine 60: 762-766, 2012.

31. Dobbs RJ, Charlett A, Purkiss AG, Dobbs SM, Weller C and Peterson DW: Association of circulating TNF-alpha and IL-6 with ageing and parkinsonism. Acta Neurol Scand 100: 34-41, 1999.

(i) (i) () This work is licensed under a Creative Commons C. Attribution-NonCommercial-NoDerivatives 4.0 International (CC BY-NC-ND 4.0) License. 